\title{
Some Structural Properties of Dynamically Drawn iPP Fibers
}

\author{
Afaf M. Ali 1,2 \\ ${ }^{1}$ Physics Department, Faculty of Applied Science, Umm AL-Qura University, Mecca, KSA \\ ${ }^{2}$ Physics Department, Faculty of Science, Mansoura University, Mansoura, Egypt \\ Email: afafmaweed@gmail.com
}

How to cite this paper: Ali, A.M. (2017) Some Structural Properties of Dynamically Drawn iPP Fibers. Optics and Photonics Journal, 7, 109-121.

https://doi.org/10.4236/opj.2017.76011

Received: May 2, 2017

Accepted: June 12, 2017

Published: June 15, 2017

Copyright $\odot 2017$ by author and Scientific Research Publishing Inc. This work is licensed under the Creative Commons Attribution International License (CC BY 4.0).

http://creativecommons.org/licenses/by/4.0/

\section{Open Access}

\begin{abstract}
Changes in the different structural parameters of iPP fibers during the dynamically cold drawing process were characterized. Using the dynamic mechanical cold drawing device attached to Fizeau interference system all the optical and structural properties can be measured. With the aid of this device the effect of the strain rate on the different structure properties was measured. The molecular orientations, molecular polarizability, molar reflectivity and shrinkage stress were measured. Reorientation of the molecules led to a significant variations in the measured structure properties of the drawn iPP fibers during applying the external tension.
\end{abstract}

\section{Keywords}

Drawing, Structural, Orientations and Refractive Indices

\section{Introduction}

Isotactic polypropylene (iPP) can be used in different applications as automotive industry, furniture, toys and etc. In the advanced fields of technology and science, polymers with enhanced mechanical, optical, thermal, and environmental properties are needed [1]. Isotactic polypropylene polymer is a semi crystalline polymer [2]. Due to the balance in their properties and cost-effectiveness, iPP has averted overall commercial application [3].

The textile characteristics can be improved by drawing process. During the drawing process an orientation of the chain occur. The degree of axial orientation is often characterized by the birefringence of the fiber. The orientations formed during the cold drawing process depend on the strain rate and drawing conditions [4] [5]. Increasing the transverse orientation of the molecules considered as the initial effect of the stretching which resulted from the alignment of the fibrils [6] [7]. The changes in different properties of fibers as optical, thermal 
and mechanical can be investigated using the different micro interferometric techniques.

Tensile test is used to enhance the molecular orientation [8] [9] [10]. The most common effects of the drawing process on the structural properties are the phase transitions, crystallization, destruction of crystals, transformation of crystal and drawing conditions [11].

Refractive index can be used as an indicator for the optical, structural and electrical properties of fibers. The birefringence is another key from the optical parameter of fiber which can be used to assess the amount of anisotropy and the amount of orientations [12]. Interferometric techniques are highly accurate techniques for measuring the optical properties of fibers [13]. Online Video Opto Mechanical device (VOM) [14] was designed to determine the mechanical, optical and structural properties of fibers at different strain rates. Sokkar et al., measured the different optical properties of iPP fibers during the dynamic cold drawing process [15].

The major objective of this work is to throw light on the effect of mechanical cold drawing and strain rate on different structural parameters of isotactic polypropylene fibers. The structural properties of iPP fiber were described by measuring the number of chains per unit volume, molecular polarizability, dielectric constant, dielectric susceptibility, molar reflectivity and Mechanical orientations.

\section{Theoretical Consideration}

To throw light on the effect of strain rate on the different structural properties of iPP fibers a mechanical device attached with multiple beam interference technique in transmission can be used [14].

\subsection{Determination of the Number of Chains per Unit Volume}

The number of chains per unit volume $N_{c}$ affect mainly on the number of crystallites. It can be calculated using the following equation [16]:

$$
F(\theta)=\frac{2}{5} N_{c}\left[D R^{2}-D R^{-1}\right]
$$

where $D R$ is the draw ratio. $F(\theta)$ is the orientation function and can be measured with the aid of the following equation:

$$
F(\theta)=\Delta n / \Delta n_{\max }
$$

$\Delta n$ is the current double refraction, and $\Delta n_{\max }$ is the maximum double refraction and is given by 0.045 [17]. The birefringence $\Delta n$ can be measured using the calculated refractive indices using the following equation [13].

$$
\Delta n=n^{\|}-n^{\perp}
$$

$n^{\|}, n^{\perp}$ are the refractive indices of the fiber. The values of them can be investigated using the following equation [13].

$$
n=n_{l}+\frac{F \lambda}{2 b A}
$$


where $F$ is the enclosed area under the fringe shift, $b$ is the interfringe spacing, $A$ is the transverse section area of the fiber. $n_{L}$ is the refractive index of the immersion liquid. $\lambda$ is the wavelength of monochromatic light used.

\subsection{Determination of the Molecular Polarizability of Polymeric Material}

The molecules polarization, can be formed by one of the following methods. By applying a field that make reoriention of the charge distributions which lead to the production of induced dipole moment. By applying a field that make orientation up to the initially randomly permanent dipole moments of the molecules. The molecular Polarizability is given by the following equation [18].

$$
P_{m}=P_{i}+P_{d}^{2} / 3 K_{B} T
$$

where $P_{i}$ is the induced polarizability, $P_{d}$ is the permanent dipole moment value and $T$ is the absolute temperature. The molecular polarizability $P_{m}$ can be measured using the following equation:

$$
p_{m}=\frac{3}{4 \pi}\left(\frac{n^{\prime 2}-1}{n^{\prime 2}+2}\right)
$$

where $n^{\prime}$ mean refractive index. $n^{\prime}$ can be measured from the following equation

$$
n^{\prime}=\left(n_{\|}+2 n_{\perp}\right) / 3
$$

\subsection{Determination of Dielectric Constant and Dielectric Susceptibility}

The following equation can be used to measure the value of the radically dielectric constant [19].

$$
D E_{\|}=\frac{1+2\left(n_{\|}^{2}-1\right) /\left(n_{\|}^{2}+2\right)}{1-\left(n_{\|}^{2}-1\right) /\left(n_{\|}^{2}+2\right)}
$$

An analog equation can be used to determine the value of $D E_{\perp}$. The dielectric susceptibility $(\eta)$ can be measured using the obtained values of dielectric constant with the aid of the following equation;

$$
\eta=\frac{D E-1}{4 \pi}
$$

\subsection{Determination of the Molar Reflectivity}

For a mole of a substance if the total polarizability values were measured, it's easy to measure the molar refractivity. The factors affecting the molar refractivity are the temperature, the pressure, and the refractive indices. The refractive indices values with the aid of Lorentz-Lorenz relation the molar refractivity can be measured [20].

$$
\frac{n^{\prime 2}-1}{n^{\prime 2}+2} \frac{M}{d}=R
$$

$d$ is the density and $M$ is molecular weight of the monomer units (42.08 mole 
weight). Using the following equation to measure the density of iPP fibers:

$$
d=\frac{n^{\prime}-0.9374}{0.6273}
$$

\subsection{Determination of the Mechanical Orientations}

The molecular orientation functions $\left\langle P_{2}(\cos \theta)\right\rangle$ and $\left\langle P_{4}(\cos \theta)\right\rangle$ provide some understanding of the mechanism of deformation. $\left\langle P_{2}(\cos \theta)\right\rangle$ can be measured using the following equations [16].

$$
\left\langle P_{2}(\cos (\theta))\right\rangle=\frac{1}{2}\left[\frac{2+U^{2}}{1-U^{2}}-\frac{3 U \cos ^{-1} U}{\left(1-U^{2}\right)^{3 / 2}}\right]
$$

where $U=D R^{-3 / 2}$.

$\left\langle P_{4}(\cos \theta)\right\rangle$ value can be measured the following equation [21]:

$$
\left\langle P_{4}(\cos (\theta))\right\rangle=\frac{1}{8}\left\{\frac{35}{\left(1-U^{2}\right)^{2}}\left[1+\frac{U^{2}}{2}-\frac{3 U \cos ^{-1} U}{2\left(1-U^{2}\right)^{\frac{1}{2}}}\right]-\frac{30}{1-U^{2}}\left[1-\frac{U \cos ^{-1} U}{\left(1-U^{2}\right)^{\frac{1}{2}}}\right]+3\right\}
$$

\section{Experimental Technique}

An automated cold drawing device (VOM) [22] connected to multiple beam interferometric technique in transmission is used due to its high accuracy in the measurements of the optical properties of sample under study. The (VOM) setup used in this work consists of three units.

1) First unit (Interferometric unit); this unit is a multiple-beam Fizeau fringes in transmission technique.

2) Second unit (Mechanical unit): it used in drawing the fiber under study and controlling the strain rate. The accuracy in measuring the strain rate is $\pm 0.0149 \mathrm{~cm} / \mathrm{s}$ [14].

3) Third unit (Computerized unit): this unit used to record the obtained video of the on line drawing process.

\section{Experimental Results and Discussions}

Fixing of iPP fibers with the gear boxes. A drop of liquid with refractive index $n_{L}$ $=1.5001$ at $T=30^{\circ} \mathrm{C}$ close to the parallel refractive index of iPP fiber was used. Light of monochromatic wavelength $546.1 \mathrm{~nm}$ was used. The strain rate was controlled by controlling the speed of the stretching device. The stepper motor velocity was adjusted using the software program installed in the computer system. The CCD camera was adjusted to record the video output images from the microscope field. The CCD camera adjusted to record 25 frames/s during the drawing process. The obtained video film was cut into separate images to deal with each frame separately. The draw ratio calculated using the VOM calibration curve [14]. The images of the cut frames were enhanced and the noises were removed by using Fourier transform method. The obtained contour lines were analyzed for the determination of fiber refractive index. To change the 
speed of drawing or the strain rate value, the frequency of the stepper motor was changed. The draw ratios values were selected in the range from 2 to 6 . Figure 1 gives some examples of the enhanced contour line from the obtained microinterferograms for iPP at different strain rate at constant $D R=4$. The direction of the vibrating light is parallel to the fiber axis. It is clear from this figure that the enclosed area under the fringe shift change during the drawing process. Which led to the change in the refractive indices with the draw ratio.

In case of perpendicular direction, a filament of the fiber was immersed in a liquid with refractive index $n_{L}=1.492$ at temperature $T=30^{\circ} \mathrm{C}$. The same steps described above were repeated carefully. Figure 2 gives some of the obtained contour line from the microinterferograms at different strain rate values. Figure $3(a)$, Figure 3(b) shows the variation of the refractive indices with the draw ratio using different strain rate, a) for parallel refractive index and b) for perpendicular refractive index. It is clear from the obtained data, the refractive index for light vibrating parallel to the fiber axis increases by increasing the strain rate and the draw ratio which mean that the chain of fiber become more oriented in this direction and a large improvement in the axial packing. The perpendicular refractive index decreases by increasing the draw ratio but its values increase with increasing the strain rate. The perpendicular refractive index values decrease by increasing the draw ratio due to a slight decrease in the radial direction. The accuracy in the refractive index measurements is \pm 0.0007 [23].
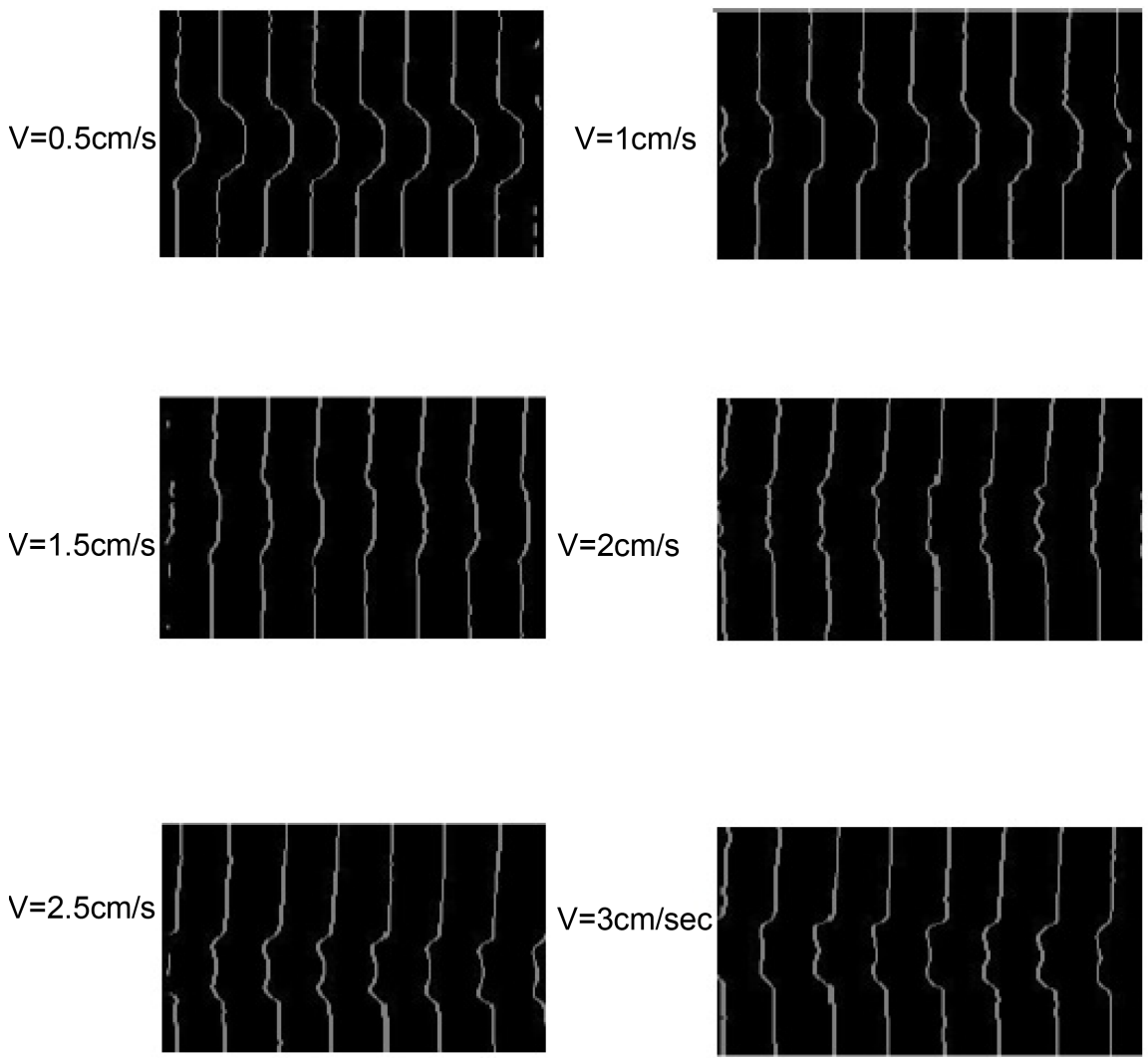

Figure 1. Gives some examples of the enhanced contour line from the obtained microinterferograms for iPP at different strain rate at constant $\mathrm{DR}=4$. 


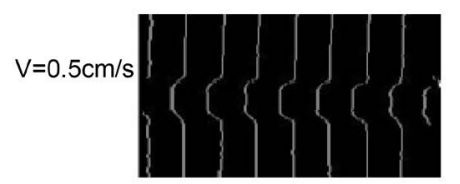

$\mathrm{V}=1 \mathrm{~cm} / \mathrm{s}$
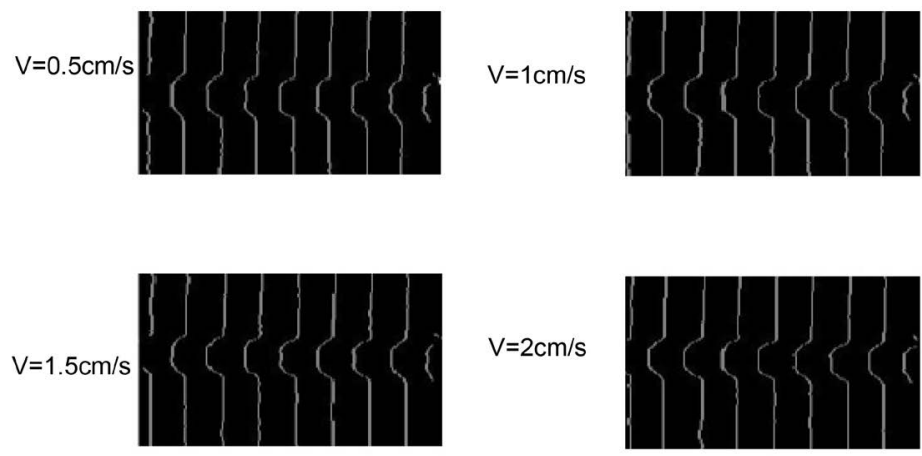

$V=2 \mathrm{~cm} / \mathrm{s}$
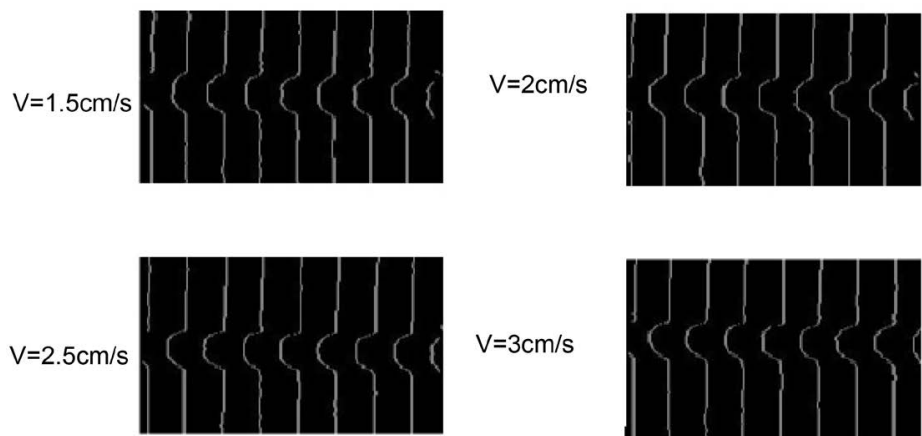

$\mathrm{V}=3 \mathrm{~cm} / \mathrm{s}$

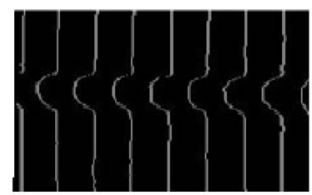

Figure 2. Gives some of the obtained contour line from the microinterferograms at different strain rate values.

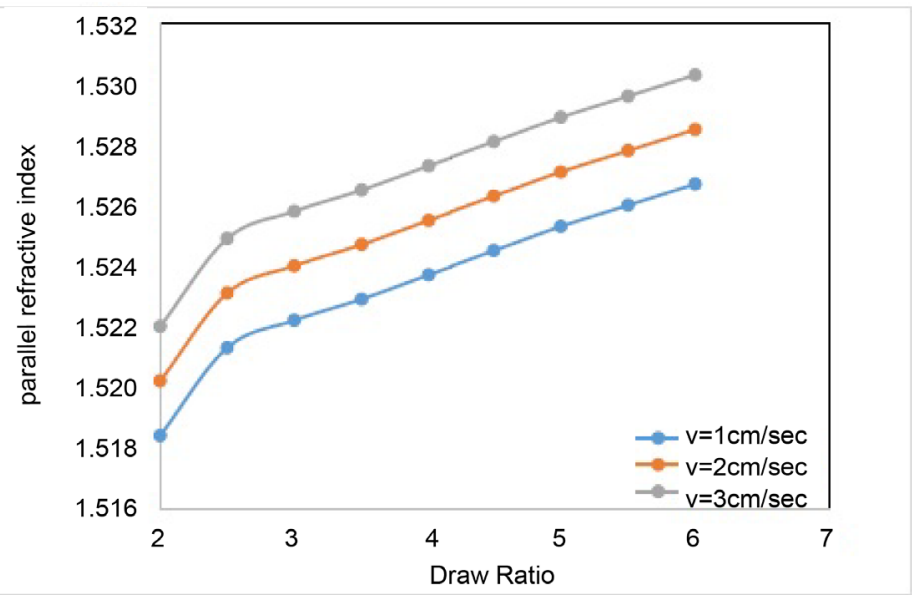

(a)

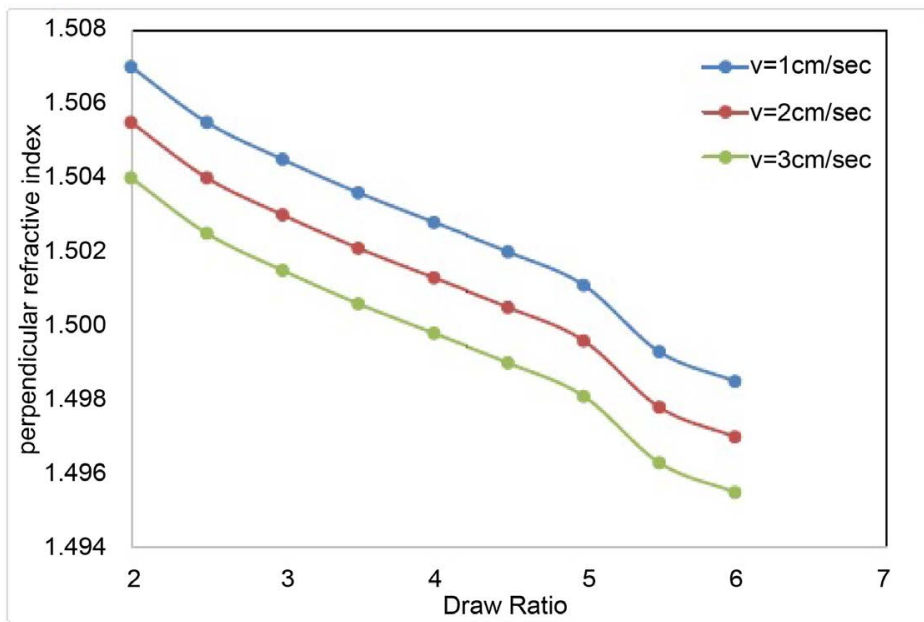

(b)

Figure 3. Shows the variation of the refractive indices with the draw ratio using different strain rate, (a) for parallel refractive index and (b) for perpendicular refractive index. 
Figure 4 shows the variation of the birefringence of iPP fibers with the draw ratio using different strain rates. It is clear that the birefringence increases with increasing the draw ratio and the strain rate. iPP fiber is a semi crystalline polymer so its birefringence is considered as an indicator of the amorphous and crystalline regions. The recorded increase in the birefringence values means the constituting molecules were aligned in parallel direction more than the perpendicular direction as a result of the on line cold drawing process [23] [24]. The alignment of molecules increases with increasing the strain rate.

The effect of the draw ratio and the strain rate on the different structural properties were investigated through the calculation of the number of chains per unit volume. Figure 5 represents the variation of the number of chains per unit volume with the draw ratio at different strain rates. From the obtained data, it is clear that as the draw ratio increases the number of chains per unit volume decreases for the same strain rate. The elastic behavior of a molecular network during the drawing process is predicted to depend only on the number of molecular chains. The number of chains per unit volume decreases as the draw ratio increases that due to the crosslink density depending mainly on the draw ratio. In this case the crystallites work as a physical crosslink point.

The molecular polarizability of iPP fibers was measured in terms of the obtained values of the refractive indices using Equations (6), Equations (7). Figure 6 shows the variation of the molecular polarizability with the draw ratio at different strain rate. From calculated data, it is clear that the molecular polarizability increases by increasing the draw ratio and the strain rate.

The variation in the obtained optical parameters measured before may be considered as a result of adjustment in the electrical properties. Dielectric constant and dielectric susceptibility were measured using Equations (8), (9). Figure 7 (a), Figure 7 (b) represents the variation of the dielectric constant with the

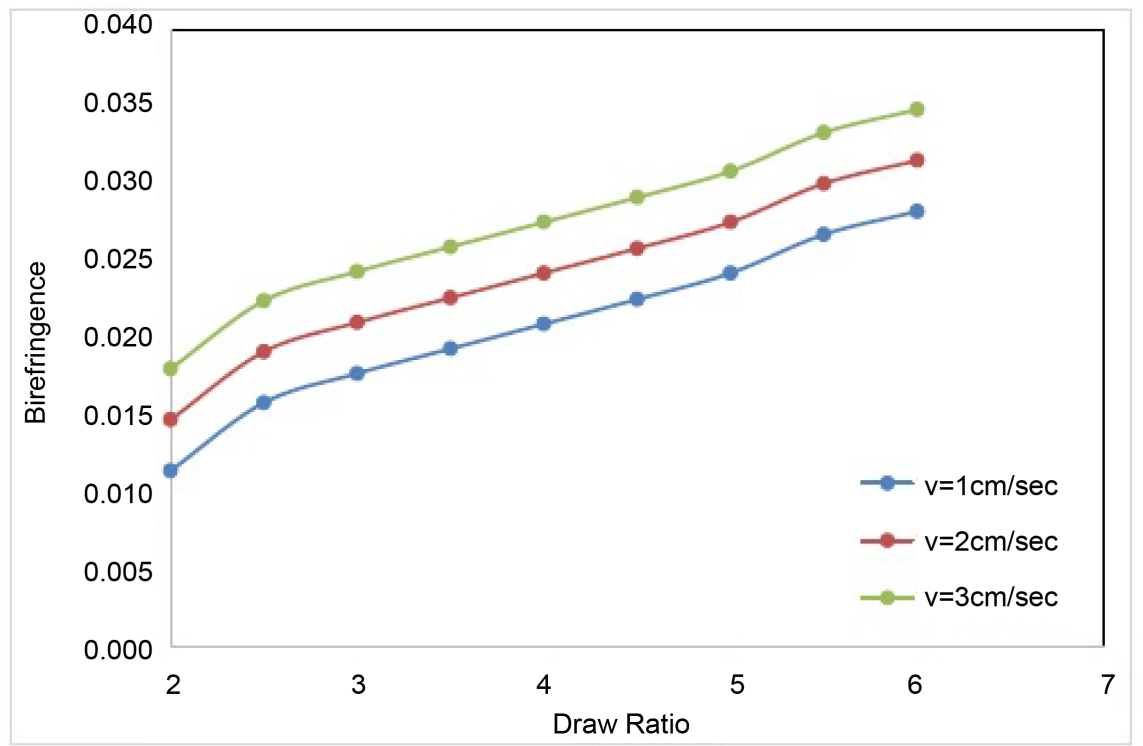

Figure 4. Shows the variation of the birefringence of iPP fibers with the draw ratio using different strain rates. 


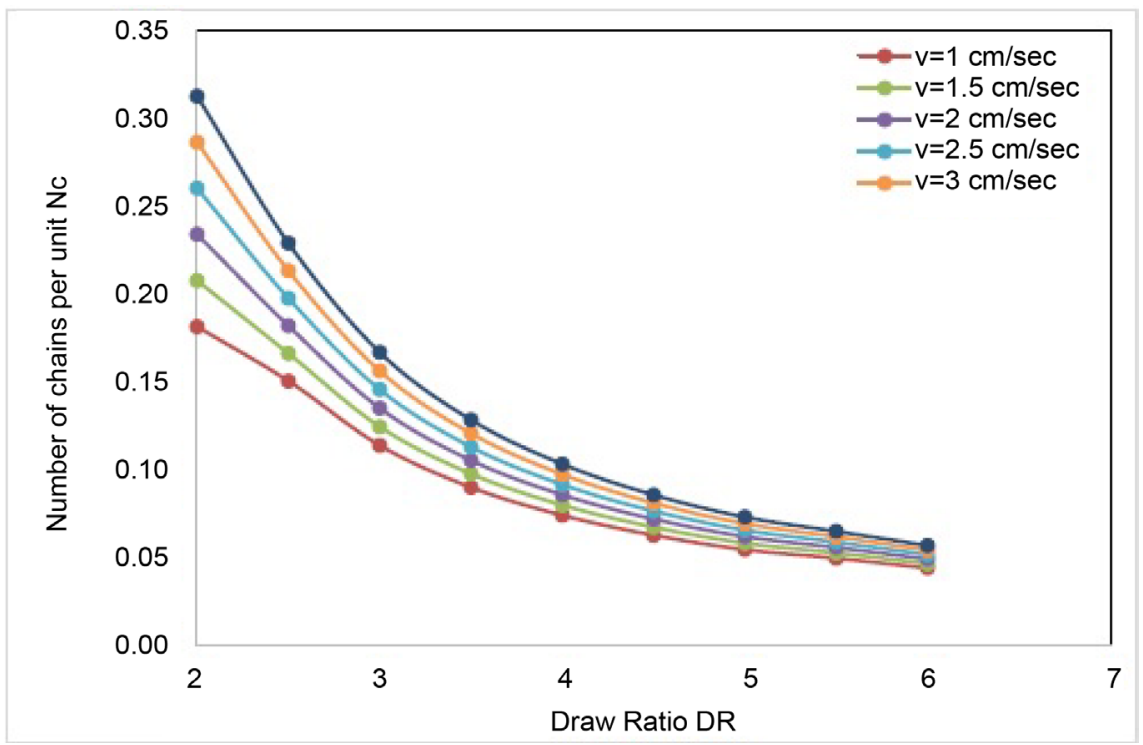

Figure 5. Represents the variation of the number of chains per unit volume with the draw ratio at different strain rates.

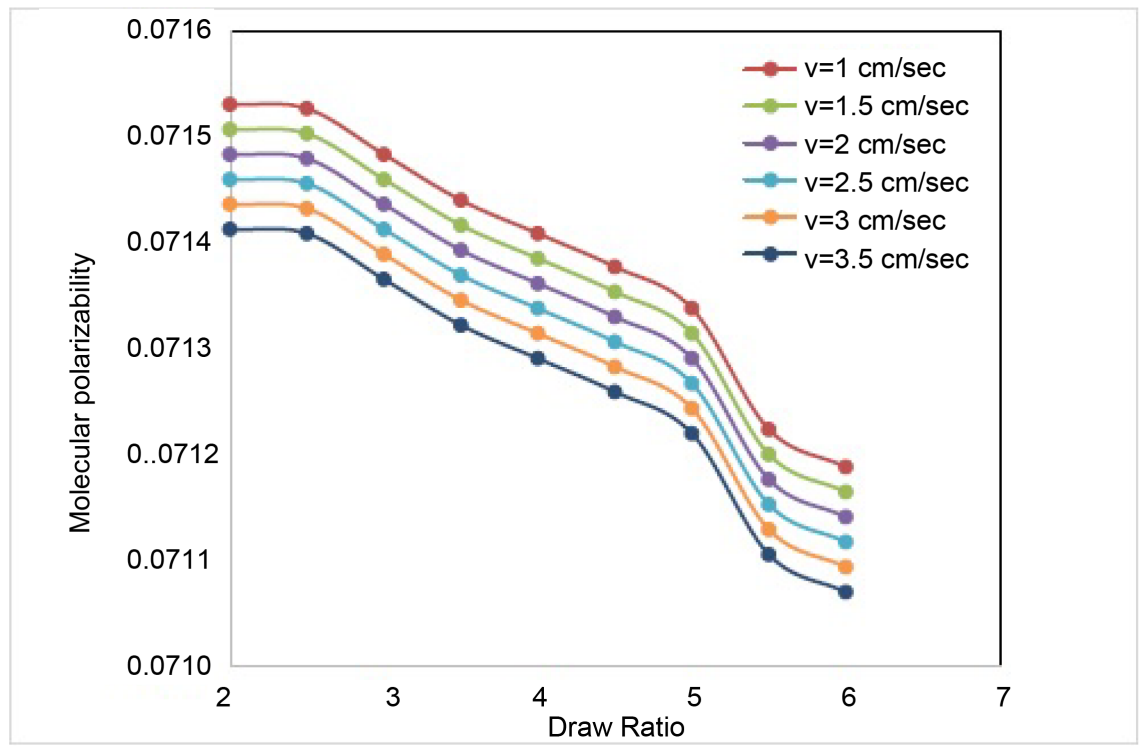

Figure 6. Shows the variation of the molecular polarizability with the draw ratio at different strain rate.

draw ratio using different strain rate, a) for parallel direction and b) for perpendicular direction. It is clear that the parallel dielectric constant increase with increasing the draw ratio and the strain rate. While the perpendicular (decrease with increasing the strain rate and the draw ratio. Figure 8(a), Figure 8(b) gives the variation of dielectric susceptibility with the draw ratio at different strain rates where, a) for parallel direction and b) for perpendicular direction. From the calculated values for dielectric susceptibility, it is clear that it follow the same behavior as the dielectric constants. Space changes and the residual electric field in the polymers after drawing at different strain rate may be considered as the most common factors affecting the variation in the values of the dielectric con- 


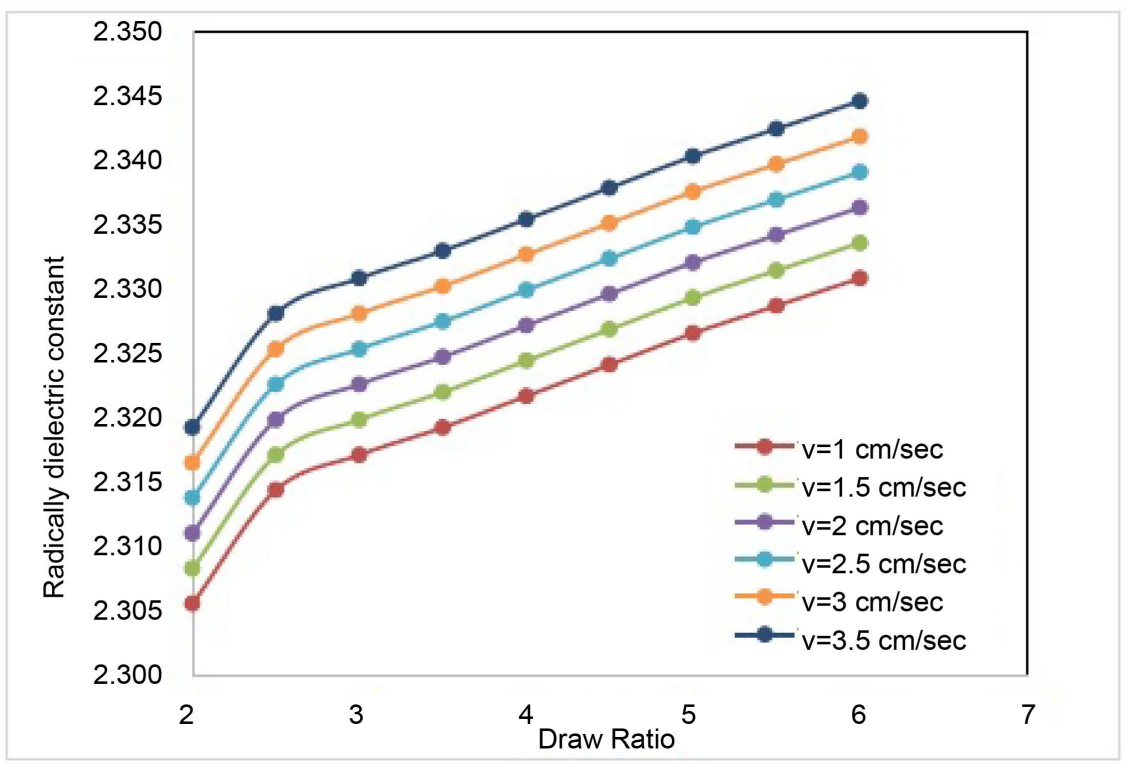

(a)

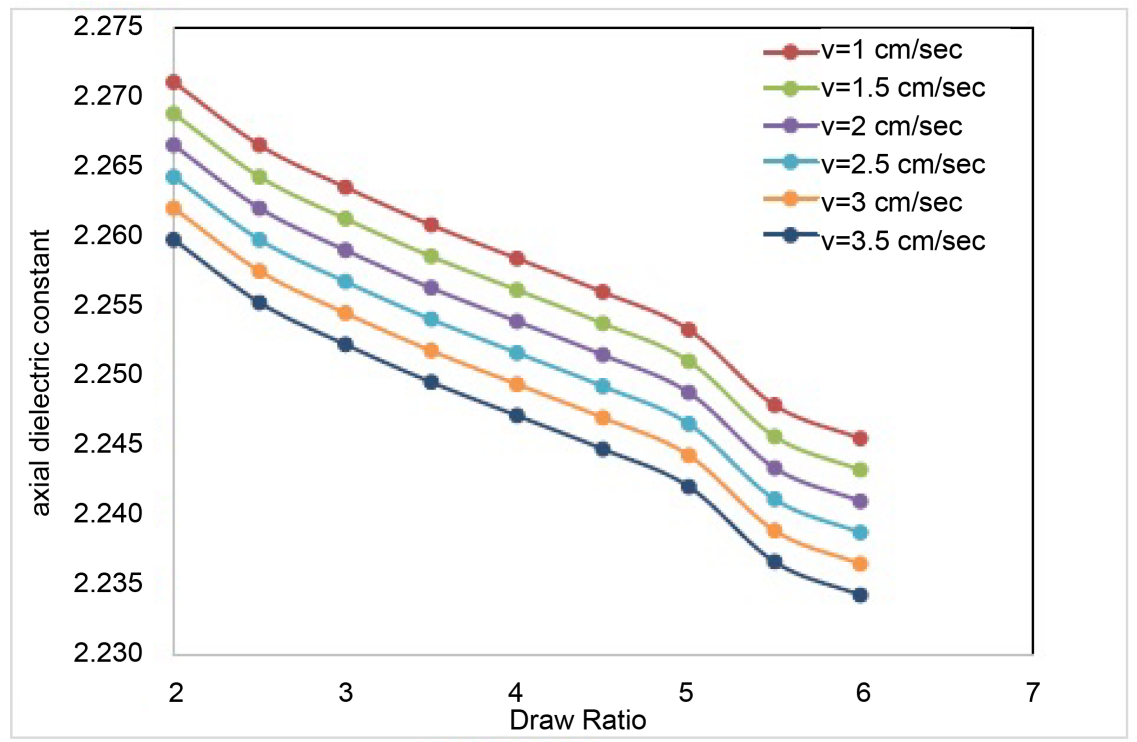

(b)

Figure 7. (a) (b) represents the variation of the dielectric constant with the draw ratio using different strain rate, a) for parallel direction and b) for perpendicular direction.

stants and the dielectric susceptibility [25].

Molar reflectivity can be considered as an indicator of the total polarizability of a mole of a substance. The molar reflectivity measured using equations (10, 11). Figure 9 gives the variation of the molar reflectivity with the draw ratio at different strain rate. It is clear the molar reflectivity that the molar reflectivity increase by increasing the draw ratio and the strain rate.

The mechanical orientation factors $\left\langle P_{2}(\cos (\theta))\right\rangle$ and $\left\langle P_{4}(\cos (\theta))\right\rangle$ are only mechanically dependent as shown in Equations $(12,13)$. Figure 10 shows the variation of the calculated $\left\langle P_{2}(\cos (\theta))\right\rangle$ with the draw ratio and Figure 11 gives the variation of $\left\langle P_{4}(\cos (\theta))\right\rangle$ with the draw ratio. It is clear that these 


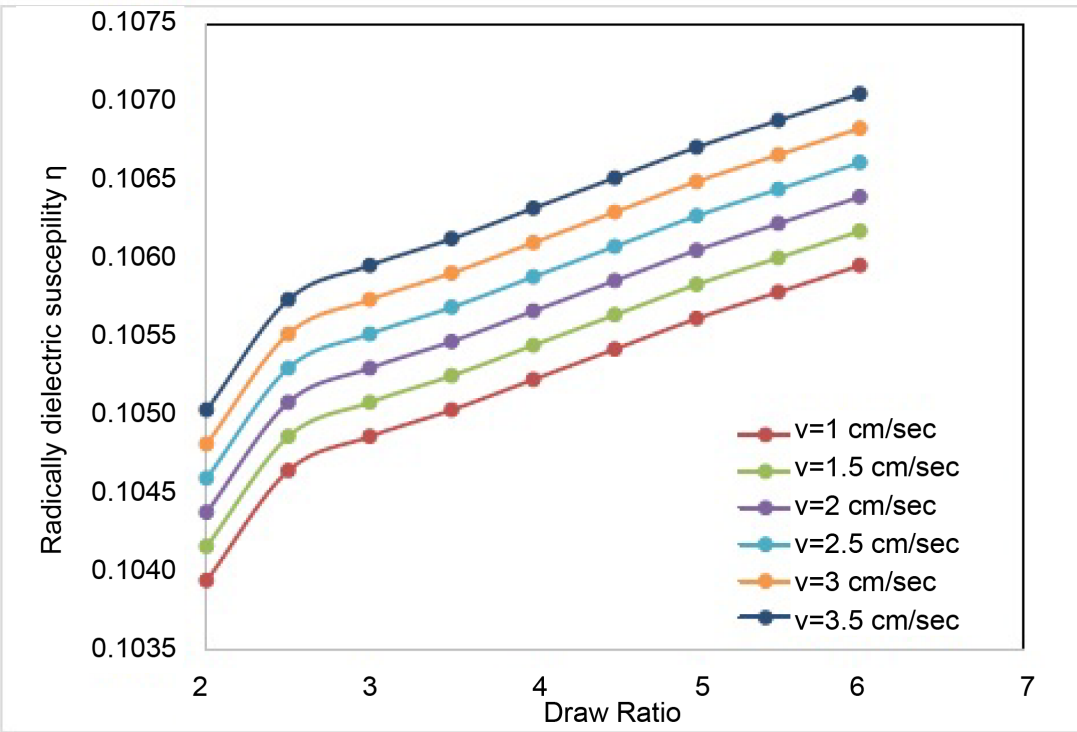

(a)

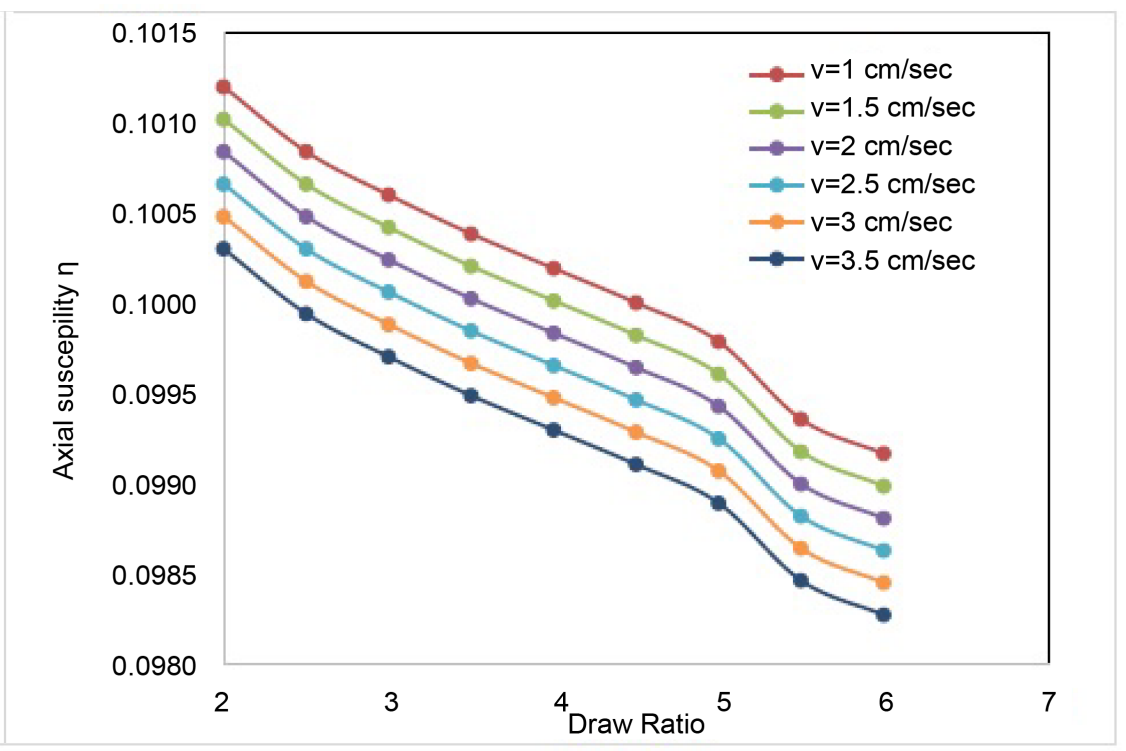

(b)

Figure 8. (a) (b) gives the variation of dielectric susceptibility with the draw ratio at different strain rates where, a) for parallel direction and b) for perpendicular direction.

mechanical orientation factors increase by increasing draw ratio and the values of $\left\langle P_{4}(\cos (\theta))\right\rangle$ are always comparatively small. It is clear that these mechanical orientation function depends mainly on the draw ratio. So most of the opto-mechanical device can be used to investigate the variation on molecular orientations.

\section{Conclusions}

Isotactic polypropylene iPP fiber is of the common semi-crystalline polymer. The results of this study prove that dynamic cold drawing process has a significant effect on the optical and structural properties of iPP fibers. The draw ratio 


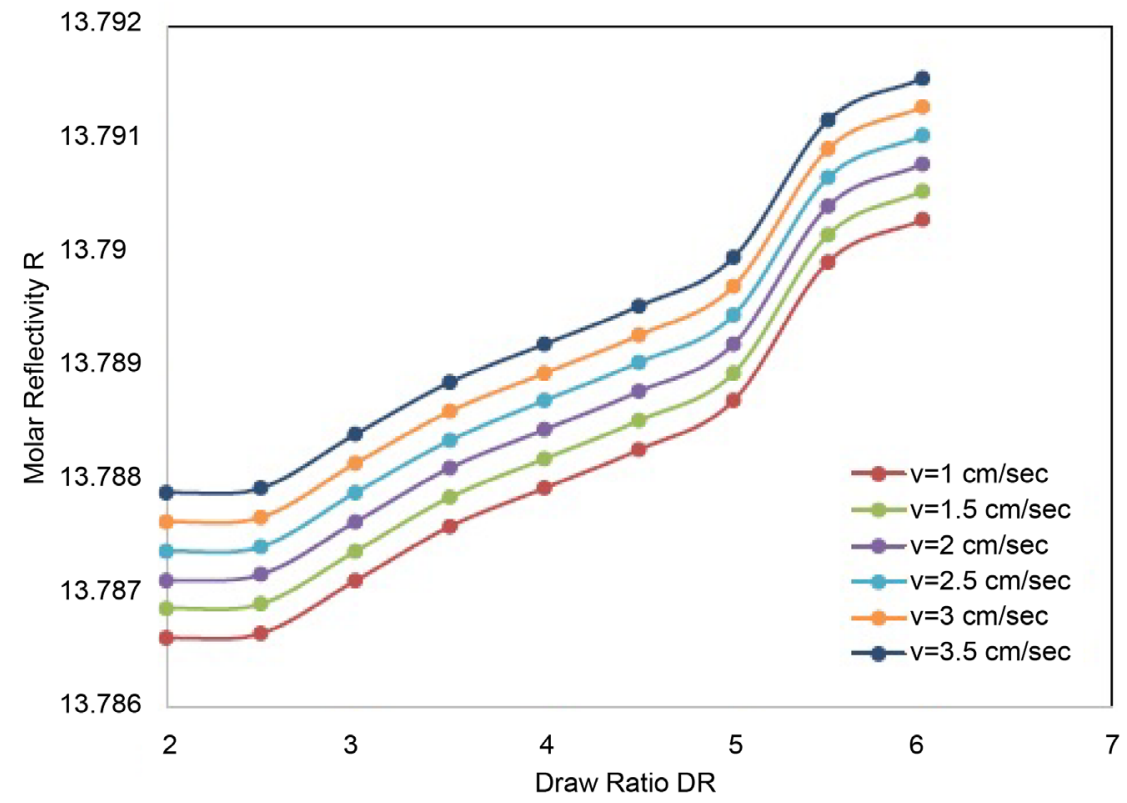

Figure 9. Gives the variation of the molar reflectivity with the draw ratio at different strain rate.

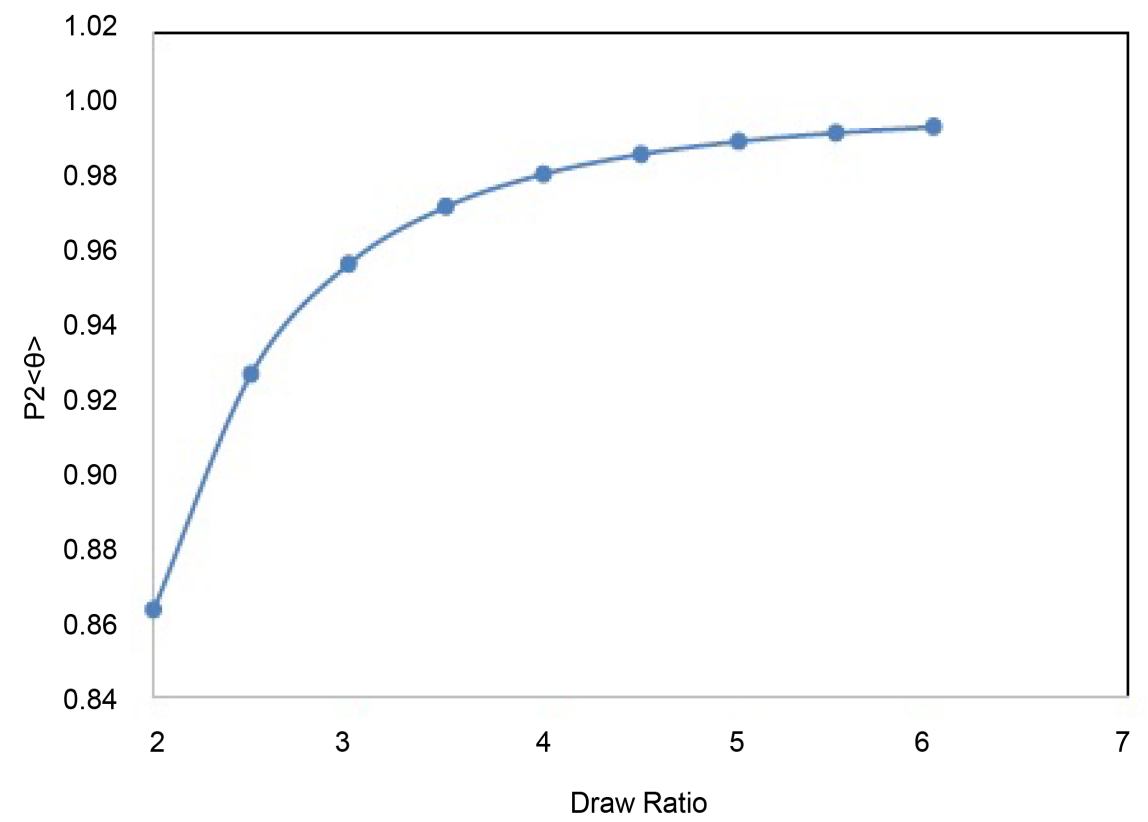

Figure 10. Shows the variation of the calculated $\left\langle P_{2}(\cos (\theta))\right\rangle$ with the draw ratio.

effect on the structural properties of iPP fibers is greater than the effect of strain rate on that physical properties. From the calculated data the following conclusions may be drawn:

1- The number of chains per unit volume decrease by increasing the draw ratio but increase with increasing the strain rate.

2- The molecular polarizability decrease by increasing the draw ratio and strain rate.

3- Both of the dielectric constants and dielectric susceptibility have the same 


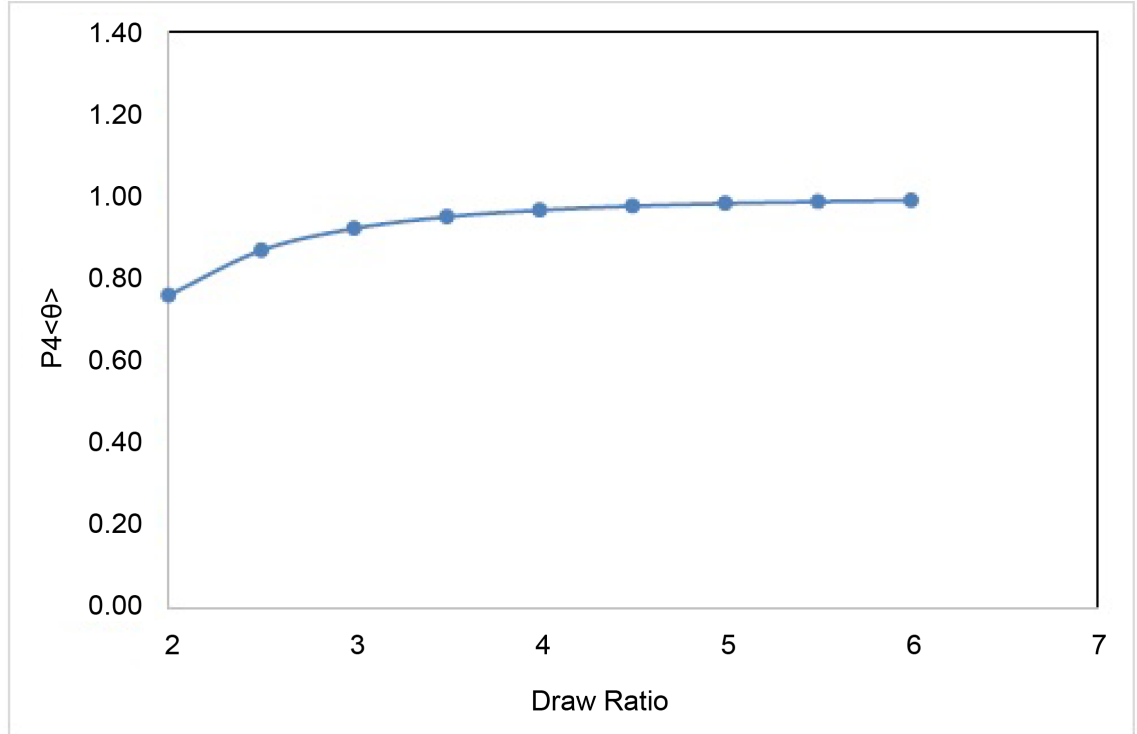

Figure 11. Gives the variation of $<P_{4}(\cos (\theta))>$ with the draw ratio.

behaviors.

4- Increasing the molar reflectivity by increasing the draw ratio and the strain rate.

\section{Acknowledgements}

The authors would like to thank the Deanship of Scientific Research at Umm Al-Qura University for the continuous support. This work was supported financially by the Deanship of Scientific Research at Umm Al-Qura University to DR Afaf M Ali. (Grant Code: 15-SCI-3-3-0011).

\section{References}

[1] Charles, E. and Carraher, Jr. (2003) Polymer Chemistry. Marcel Dekker, New York.

[2] Longo, C., Savaris, M., Zeni, M., Brandalise, R.N. and Grisa, A.M.C. (2011) Degradation Study of Polypropylene (PP) and Bioriented Polyproylene (BOPP) in the Environment. Materials Research, 14, 442. https://doi.org/10.1590/S1516-14392011005000080

[3] Junkasem, J., Menges, J. and Supaphol, P. (2006) Mechanical Properties of Injection-Molded Isotactic Polypropylene/Roselle Fiber Composites. Journal of Applied Polymer Science, 101, 3291. https://doi.org/10.1002/app.23829

[4] Sokkar, T.Z.N., Shams El-Din, M.A. El-Tawargy, A.S. (2012) On Young’s Modulus Profile across Anisotropic Nonhomogeneous Polymeric Fibre Using Automatic Transverse Interferometric Method. Optics and Lasers in Engineering, 50, 1223.

[5] Tager, A. (1978) Physical Chemistery of Polymers. MIR, Moscow.

[6] Hearle, J.W.S. (1963) The Fine Structure of Fibers and Crystalline Polymers. I. Fringed Fibril Structure. Journal of Applied Polymer Science, 7, 1175.

https://doi.org/10.1002/app.1963.070070401

[7] Hearle, J.W.S. (1963) The Fine Structure of Fibers and Crystalline Polymers. II. The Growth of Crystalline Regions in Fibers. Journal of Applied Polymer Science, 7, 1193. https://doi.org/10.1002/app.1963.070070402 
[8] Chen, X. (2016) Advanced Fibrous Composite Materials for Ballistic Protection. Wood Head, Glossop, UK.

[9] Zachariades, A.E. and Porter, R.S. (1988) High Modulus Polymers. Marcel Dekker, New York.

[10] Ward, I.M. (1997) Structure and Properties of Oriented Polymers. 2nd Edition, Chapman and Hall, London. https://doi.org/10.1007/978-94-011-5844-2

[11] Walezak, Z.K. (1977) Formation of Synthetic Fibers. Chap. 6, Gordon and Breach Science Publishers, New York.

[12] Inoue, T., Hwang, E. and Osaki, K. (1997) Birefringence of Amorphous Polyarylates: 2. Dynamic Measurement on a Polyarylate with Low Optical Anisotropy. Polymer, 38, 1029-1034. https://doi.org/10.1016/S0032-3861(96)00605-2

[13] Barakat, N. and Hamza, A.A. (1990) Interferometry of Fibrous Materials. Adam Hilger, New York, Bristol.

[14] Sokkar, T.Z.N., El-Tonsy, M., El-Bakary, M.A., El-Morsy, M.A. and Ali, A.M. (2009) A Novel Video Opto-Mechanical (VOM) Device for Studying the Effect of Stretching Speed on the Optical and Structural Properties of Fibers. Optics \& Laser Technology, 41, 310-317. https://doi.org/10.1016/j.optlastec.2008.05.027

[15] Sokkar, T.Z.N., El-Bakary, M.A. and Ali, A.M. (2013) The Influence of Mechanical Cold Drawing and Drawing Velocity on the Molecular Structure of Isotactic Polypropylene Fiber. Journal of Applied Polymer Science, 127, 1105-1113. https://doi.org/10.1002/app.37559

[16] Stein, R.S. (1959) The Orientation of Polyethylene. Journal of Polymer Science Part A: Polymer Chemistry, 34, 709-720. https://doi.org/10.1002/pol.1959.1203412747

[17] Fouda, I.M., El-Tonsy, M.M., Seisa, E.A. and Felfel, R.M. (2011) Structure Characterization of Cold Drawn High Density Polyethylene Thin Film. Journal of Applied Polymer Science, 122, 2026-2032. https://doi.org/10.1002/app.34123

[18] Jackson, J.D. (1975) Classical Electrodynamics. USA.

[19] Fouda, I.M. and Siesa, E.A. (2009) The Activation Energy and Some Structural Parameters of Thermally Treated Polypropylene Suture Fibers. International Journal of Polymeric Materials and Polymeric Biomaterials, 58, 191-201. https://doi.org/10.1080/00914030802639940

[20] Fouda, I.M. and Shabana, H.M. (1999) Contribution of Interferometry and Mechanical Parameters in Evaluating Molecular Orientation for Drawn Polyester. Polymer International, 48, 602-606. https://doi.org/10.1002/(SICI)1097-0126(199907)48:7<602::AID-PI193>3.0.CO;2-X

[21] Treloar, L.R.G. (1958) Physics of Rubber Elasticity. 2nd Edition, Oxford University Press, London.

[22] Hamza, A.A., Sokkar, T.Z.N., El-Morsy, M.A., Raslan, M.I. and Ali, A.M. (2010) 3D Refractive Index Profile for the Characterization of Necking Phenomenon along Stretched Polypropylene Fibres. Optics Communications, 283, 1684-1689. https://doi.org/10.1016/j.optcom.2009.12.059

[23] Hamza, A.A. and Kabeel, M.A. (1986) Multiple Beam Fizeau Fringes Crossing a Cylindrical Multi Layer Fibers. Journal of Physics D: Applied Physics, 19, 175. https://doi.org/10.1088/0022-3727/19/7/007

[24] Hamza, A.A., Sokkar, T.Z.N., El-Bakary, M.A. and Ali, A.M. (2010) On Line Interferometric Investigation of the Neck Propagation Phenomena of Stretched Polypropylene Fibre. Optics \& Laser Technology, 42, 703-709. https://doi.org/10.1016/j.optlastec.2009.11.007

[25] Kuleznev, V.N. and Shershnev, V.A. (1990) The Chemistry and Physics of Polymers. Mir, Moscow. 
Submit or recommend next manuscript to SCIRP and we will provide best service for you:

Accepting pre-submission inquiries through Email, Facebook, LinkedIn, Twitter, etc. A wide selection of journals (inclusive of 9 subjects, more than 200 journals)

Providing 24-hour high-quality service

User-friendly online submission system

Fair and swift peer-review system

Efficient typesetting and proofreading procedure

Display of the result of downloads and visits, as well as the number of cited articles Maximum dissemination of your research work

Submit your manuscript at: http://papersubmission.scirp.org/

Or contactopj@scirp.org 